\title{
PENERAPAN PRINSIP-PRINSIP KOMUNIKASI ISLAM OLEH PT ULFA RIZKI DALAM MENSOSIALISASIKAN IBADAH HAJI DAN UMRAH DI KOTA MEDAN
}

\author{
Nurul Saniah, Muallimah, Indah Lestari \\ Penulis adalah Dosen Universitas Potensi Utama \\ (Jl. K.L. Yos Sudarso Km 6,5 No 3 A Telp. 0616640525 Fax. 0616636830 ) \\ Tanjung Mulia Medan (20241) \\ Email: info@potensi-utama.ac.id website: www.potensi-utama.ac.id
}

\begin{abstract}
Abstrak
Tujuan penelitian ini adalah untuk mendeskripsikan bagaimana penerapan prinsipprinsip komunikasi Islam, kegiatan-kegiatan dan fasilitas PT Ulfa Rizki dalam mensosialisasikan ibadah haji dan umrah di kota Medan, dan respon masyarakat terhadap PT Ulfa Rizki dalam mensosialisasikan ibadah haji dan umrah di kota Medan. Metode Penelitian ini adlaah kualitatif yang menitikberatkan pada penelitian studi kasus, yaitu penelitian yang lebih mendetail, mendalam dan lebih intensif kepada PT Ulfa Rizki. Sumber data yang digunakan yaitu data primer (data pokok) adalah PT Ulfa Rizki, karyawan dan staff juga merupakan data primer dalam penelitian ini, dan data sekunder (data tambahan) penulis peroleh dari masyarakat yang mengetahui PT Ulfa Rizki dan beberapa buku-buku literatur yang berkaitan dengan penelitian. Instrumen pengumpulan data yang peneliti gunakan ialah observasi, wawancara dan studi dokumen. Berdasarkan hasil penelitian, dapat diketahui bahwa PT Ulfa Rizki telah menerapkan prinsip- prinsip komunikasi Islam dalam mensosialisasikan ibadah haji dan umrah yaitu menyampaikan perkataan yang benar, perkataan yang berbekas pada jiwa, perkataan yang pantas (mudah dipahami), perkataan yang lemah lembut, perkataan yang baik dan perkataan yang mulia. Adapun kegiatan yang diberikan PT Ulfa Rizki pada para jamaah ialah pelatihan manasik, zikir dan muhasabah dan pengajian Alquran. Selain itu juga melakukan ziarah ke beberapa tempat di kota Mekah dan Madinah. Sedangkan fasilitas yang diberikan tergantung pada jenis umrah yang dipilih. Untuk haji, travel PT Ulfa Rizki hanya menyediakan haji khusus/ haji plus. Respon masyarakat terhadap sosialisasi yang dilakukan PT Ulfa Rizki bermacammacam. Ada yang menerima dan ada pula yang menolak dengan alasan- alasan tertentu.
\end{abstract}

Kata kunci: Prinsip-prinsip Komunikasi Islam, Sosialisasi, Haji dan Umrah

\section{PENDAHULUAN}

Komunikasi bisa terjadi dimana saja, misalnya: dirumah, ketika anggota keluarga berbincang dimeja makan; dikampus, ketika mahasiswa mendiskusikan hasil karya ilmiahnya; dikantor, ketika kepala seksi membagi tugas kepada anak buahnya; di mesjid, ketika muballigh berkhutbah sehingga komunikasi menyentuh segala aspek kehidupan kita. Komunikasi menentukan kualitas hidup kita, dan komunikasi juga mempengaruhi perkembangan jiwa manusia. (Fajar: 2009) 
Komunikasi adalah cara untuk membangun ikatan yang kuat dengan orangorang di sekitar kita, termasuk dalam melakukan pekerjaan. Dengan adanya komunikasi, kita juga bisa belajar memahami apa yang mereka perlukan atau inginkan. Komunikasi juga bisa disampaikan secara verbal dan non-verbal. Komunikasi nonverbal bisa mencakup semua jenis ekspresi emosional, tindakan, bahasa tubuh, dan kata-kata yang berarti. Dengan membentuk komunikasi yang baik, diharapkan mereka juga akhirnya dapat mengungkapkan pikiran dengan cara yang lebih baik.

Dalam Islam juga di atur bagaimana seseorang berkomunikasi dengan baik pada orang lain, sehingga lahirlah yang disebut dengan Ilmu Komunikasi Islam. Komunikasi Islam merupakan bidang kajian baru yang menarik perhatian sebagian akademisi di berbagai perguruan tinggi. Keinginan untuk melahirkan komunikasi Islam muncul akibat falsafah, pendekatan teoritis, dan penerapan ilmu komunikasi yang berasal dan dikembangkan di Barat dan Eropa tidak sepenuhnya sesuai dengan nilai-nilai agama dan budaya Islam. Karena itu, timbul keinginan untuk mengkaji kembali berbagai aspek Ilmu Komunikasi menurut perspektif agama, budaya dan cara hidup umat Islam. (Kholil:2009)

Dari paparan di atas begitu pentingnya Ilmu Komunikasi Islam untuk umat Islam sendiri agar manusia bisa menerapkan komunikasi dalam Islam dan berpedoman kepada Alquran dan Hadis. Komunikasi Islam adalah proses penyampaian pesan antara komunikator kepada komunikan dengan menggunakan prinsp-prinsip komunikasi Islam yang ada di dalam Alquran dan hadis. Dengan tujuan amar ma'ruf nahi munkar (menyuruh yang baik dan melarang yang munkar).

Penggunan prinsip- prinsip komunikasi Islam bukan hanya diperlukan dalam dunia dakwah dan pendidikan saja tapi juga penting bagi mereka yang bergelut dalam bidang travel seperti travel haji dan umrah. Namun, beberapa kasus yang terjadi belakangan ini terkait penyelewengan/ penipuan dana haji dan umrah oleh oknumoknum pada beberapa travel, tentunya membuat para calon jamaah merasa was- was dan berhati- hati memilih travel untuk perjalanan ibadah haji dan umrah mereka.

Sebagai salah satu sarana dalam memfasilitasi ibadah haji dan umrah, PT UIFA RIZKI yang bergerak di dalam bidang travel juga sangat membutuhkan komunikasi yang baik dalam mensosialisasikan kegiatan-kegiatannya. Oleh karena itu, PT Ulfa Rizki tersebut juga harus menerapkan prinsip-prinsip komunikasi Islam yang baik sehingga masyarakat yakin bahwa travel PT Ulfa Rizki benar- benar 
bertanggungjawab pada keamanan dan kenyamanan para jamaahnya dalam beribadah dan berziarah, sehingga diharapkan travel ini semakin dipercaya dan diminati oleh masyarakat.

Berdasarkan observasi awal, PT Ulfa Rizki termasuk travel yang masih dalam tahap berkembang dan bisa dilihat dari bangunan yang masih berbentuk ruko, memiliki tiga orang karyawan, PT Ulfa Rizki tidak memiliki website namun memanfaatkan media sosial seperti youtube, facebook dan instagram sebagai salah satu cara mensosialisasikan kegiatan-kegiatan mereka. Dari brosur dan foto- foto yang terpajang di dinding menunjukkan bahwa travel ini telah beberapa kali memberangkatkan para jamaahnya ke tanah suci Mekah. Bila dilihat dari lokasi penelitian, travel ini bersebelahan dengan travel lain yang juga merupakan travel haji dan umrah.

Tujuan penelitian ini ialah untuk mendeskripsikan penerapan prinsip-prinsip komunikasi Islam antara karyawan PT Ulfa Rizki dengan masyarakat, mendeskripsikan kegiatan-kegiatan dan fasilitas yang ditawarkan PT Ulfa Rizki dalam mensosialisasikan ibadah haji dan umrah di kota Medan dan mendeskripsikan respon masyarakat terhadap PT Ulfa Rizki dalam mensosialisasikan ibadah haji dan umrah di kota Medan

\section{METODOLOGI PENELITIAN}

Untuk mencapai hasil yang optimal, sistematis, serta dapat dipertanggungjawabkan secara ilmiah, maka sebuah penelitian harus mempunyai metode tertentu sebagai suatu sistem atau aturan dalam menentukan jalan guna mencapai pengertian baru pada bidang ilmu pengetahuan.

\section{Jenis, Subjek dan Informan Penelitian}

Adapun jenis penelitian ini adalah penelitian kualitatif yang menititikberatkan pada penelitian studi kasus. Studi kasus merupakan tipe pendekatan dalam penelitian yang penelaahannya kepada satu kasus dilakukan secara intensif, mendalam mendetail, dan komprehensif. (Faisal: 2008)

Sedangkan subjek penelitian ini adalah direktur PT Ulfa Rizki yang secara sekaligus sebagai koordinator dan pembimbing para jamaah. Sementara informan penelitian terdiri dari orang- orang yang dapat memberikan informasi tentang prinsipprinsip komunikasi Islam dan kegiatan yang diterapkan PT Ulfa Rizki dalam mensosialisasikan ibadah haji dan umrah seperti para karyawan PT Ulfa Rizki, para 
jamaah yang sudah pernah berangkat bersama travel PT Ulfa Rizki, masyarakat sekitar PT Ulfa Rizki dan direktur Auliya Travel yang letaknya bersebelahan dengan travel Ulfa Rizki.

\section{Instrumen Pengumpulan Data}

Instrumen pengumpulan data dalam penelitian ini menggunakan observasi, wawancara dan studi dokumen. Adapun cara/ teknik yang dilakukan peneliti untuk untuk mendalami instrumen pengumpulan data ialah sebagai berikut:

\section{a. Observasi (pengamatan)}

Observasi dimaksudkan untuk mengamati prinsip- prinsip komunikasi yang diterapkan oleh PT Ulfa Rizki, kegiatan- kegiatan dan fasilitas- fasilitas yang diberikan serta respon masyarakat terhadap PT Ulfa Rizki untuk mensosialisasikan ibadah haji dan umrah, dengan terlebih dahulu mempersiapkan pedoman tertulis tentang aspekaspek yang akan diobservasi (pedoman observasi) sehingga peneliti dapat menemukan data dan informasi secara langsung serta alamiah dari peristiwa yang berlangsung. Hasil observasi ini sekaligus akan digunakan sebagai analisis silang terhadap data yang diperoleh melalui wawancara dan studi dokumen.

\section{b. Wawancara}

Adapun wawancara pada penelitian ini ditujukan kepada direktur sekaligus sebagai koordinator dan pembimbing para jamaah PT Ulfa Rizki sebagai subjek penelitian serta narasumber data dan informasi. Di samping itu, juga wawancara dilakukan kepada para karyawan PT Ulfa Rizki, para jamaah yang sudah pernah berangkat menggunakan travel PT Ulfa Rizki, masyarakat sekitar lokasi penelitian dan direktur travel Auliya yaitu Bapak Ramadhan, Lc. yang berada di samping PT Ulfa Rizki untuk mencari data dan informasi yang pendukung yang selanjutnya dijadikan bahan triangulasi.

\section{c. Studi dokumen}

Studi dokumen dalam penelitian ini juga akan mencakup penelusuran informasi dan data yang relevan atau yang dapat membantu pemahaman peneliti tentang masalah yang di studi melalui data- data dokumentasi, seperti foto- foto, rekaman video, brosur, dan dokumen- dokumen grafis.

\section{Teknik Analisis Data}

Adapun langkah- langkah yang peneliti gunakan dalam menganalisis data secara teknis mengacu pada langkah- langkah yang dikemukakan oleh Miles dan 
Huberman. Siklus analisis data kualitatif menurut Miles dan Huberman adalah sebagai berikut:

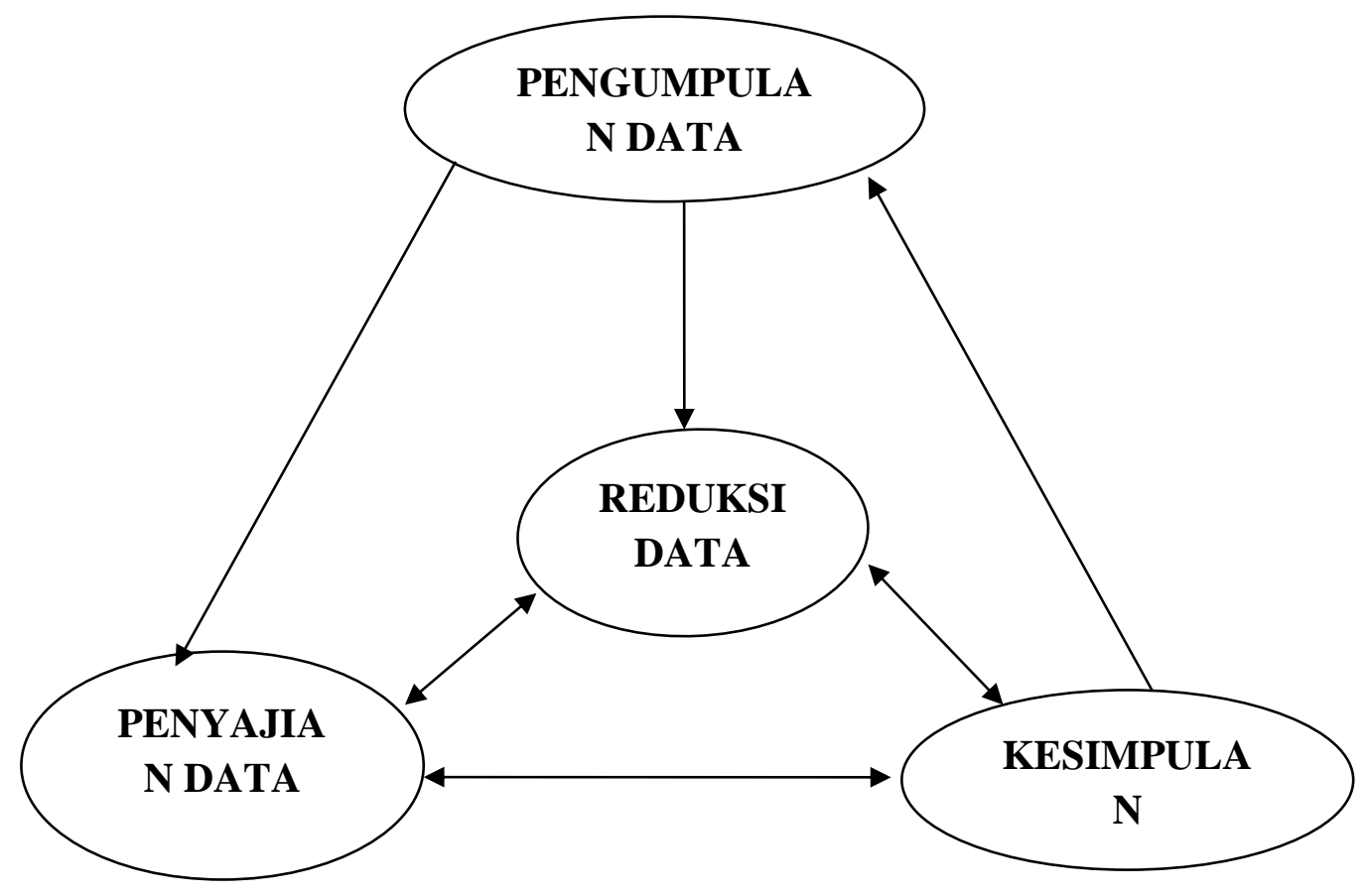

a) Reduksi Data

Miles dan Huberman mendefinisikan reduksi data sebagai suatu proses pemilihan, memfokuskan pada penyederhanaan, pengabstrakan, dan transformasi data mentah (kasar) yang muncul dari catatan- catatan tertulis di lapangan. (Miles \& Huberman;1992, 12).

b) Penyajian Data

Proses penyajian data ini adalah mengungkapkan secara keseluruhan dari sekelompok data yang diperoleh agar mudah dibaca.

c) Kesimpulan

Miles dan Huberman menjelaskan bahwa kesimpulan pada awalnya masih longgar, namun kemudian meningkat menjadi lebih rinci dan mendalam dengan bertambahnya data dan akhirnya kesimpulan merupakan suatu konfigurasi yang utuh. (1992: 13). 


\section{HASIL DAN PEMBAHASAN}

\section{Penerapan Prinsip-prinsip Komunikasi Islam Oleh PT Ulfa Rizki Kepada Calon Jamaah Haji dan Umrah}

Untuk lebih jelasnya di bawah ini penulis akan membahas penerapan prinsipprinsip komunikasi Islam oleh karyawan dan staf PT Ulfa Rizki dalam mensosialisasikan ibadah haji dan umrah di kota Medan

\section{a. Menyampaikan pesan komunikasi dengan menggunakan perkataan yang benar.}

Seorang komunikator dalam menyampaikan pesan komunikasi kepada komunikannya hendaklah harus dengan perkataan yang benar. Tidak berdusta dan berbohong, agar apa yang disampaikan komunikator tersebut bisa diterima komunikan. Begitu juga dengan pimpinan dan karyawan Ulfa Rizki berkomunikasi dengan calon jamaahnya dengan perkataan yang benar, tidak memberikan janji-janji yang baik tapi hasilnya tidak sesuai keinginan.

Beberapa staf dan karyawan PT Ulfa Rizki menyampaikan pesan komunikasi yang benar kepada calon jamaahnya, memberikan brosur kepada calon jamaah haji dan umrah sesuai dengan apa adanya tidak ada yang ditambah-tambahi maupun dikurangi. Buktinya para jamaah tidak perlu menunggu terlalu lama untuk keberangkatan umrah, dalam satu bulan PT Ulfa Rizki bisa memberangkatkan dua sampai tiga kali keberangkatan paling sedikit 50 orang jamaah bahkan bisa sampai 200 jamaah.

\section{b. Menyampaikan pesan komunikasi dengan perkataan yang berbekas}

Setiap pesan yang ingin disampaikan kepada orang lain dengan harapan bahwa pesan yang disampaikan tersebut bisa diterima oleh komunikan dan berbekas pada jiwa mereka yang mendapat informasi dari pesan komunikasi itu. Dalam memberikan penjelasan kepada calon jamaah haji dan umrah karyawan PT Ulfa Rizki selalu memberikan informasi apa yang ada dalam visi dan misi travel mereka. Biasanya calon jamaah umrah ditemani oleh pimpinannya dalam menjalankan ibadah umrah ke tanah suci dengan memberikan motivasi kepada nasabah untuk pergi haji atau umrah dengan niat dan tekad yang kuat. Para nasabah travel merasa tersentuh dan bergetar hatinya dan berniat untuk melaksanakan umrah dan haji.

\section{c. Ucapan yang pantas}

Berbicara dengan orang lain hendaklah dengan ucapan yang pantas tidak menyinggung perasaan orang lain. Dalam hal ini pimpinan dan karyawan PT Ulfa 
Rizki biasanya berbicara kepada calon jamaahnya dengan ucapan yang pantas yang mudah dipahami.

Dalam komunikasi antara karyawan dan calon jamaah haji dan umrah harus dengan perkataan yang pantas, agar apa yang ingin disampaikan karyawan bisa diterima oleh jamaahnya. Begitu pula dalam mensosialisasikan ibadah haji dan umrah pimpinan dan karyawan harus mengucapkan perkataan yang pantas agar calon jamaahnya merasa nyaman dan tertarik untuk bergabung dengan travel tersebut. Dengan memberikan sarana dan fasilitas yang lengkap sesuai dengan administrasi yang tertera.

\section{d. Perkataan yang lemah lembut}

Tegas bukan berati marah dan lembut bukan berarti lemah. Perkataan yang lemah lembut akan disukai orang lain. Begitu pula jika perkataan lemah lembut yang disampaikan oleh PT Ulfa Rizki dalam mensosialisasikan ibadah haji dan umrah kepada calon jamaahnya seperti hasil wawancara dengan direktur PT Ulfa Rizki yang juga sebagai koordinator para jamaah beliau menuturkan “ Bapak/Ibu menunggu keberangkatan di Airport ini atau pun berjam-jam di dalam pesawat juga merupakan ibadah. Bukan hanya umrahnya saja rintangan yang kita hadapi sebelum sampai disana kalau kita sabar juga termasuk dalam ibadah".

\section{e. Perkataan yang mulia}

Perkataan yang mulia harus selalu diucapkan dalam berkomunikasi dengan siapa saja dan harus disampaikan kepada semua orang termasuk orang yang lebih tua dari kita. Dan harus digunakan dimana saja kita berada pada saat berkomunikasi dengan orang lain. Begitu juga PT Ulfa Rizki dalam berkomunikasi dengan jamaahnya.

\section{f. Kata-kata yang baik}

Setiap kata-kata yang ingin disampaikan kepada orang lain hendaklah dengan kata-kata yang baik. Agar respon orang tersebut baik kepada yang menyampaikan pesan. Tetapi tidak selamanya kata-kata yang baik itu dimaknai baik oleh orang lain. Karena manusia memiliki pandangan dan cara berpikir yang berbeda-beda. Seperti baik menurut seseorang belum tentu baik menurut orang lain.

Seperti wawancara dengan direktur PT Ulfa Rizki: "kami terutama saya sering menyampaikan bahwa kami sangat berterima kasih kepada para jamaah yang sudah mempercayakan travel kami untuk perjalanan haji adan umrah mereka, karena 
beberapapersen dari hasil umrah dan haji diwakafkan untuk pembangunan pesantran Tahfiz Qur'an As-Sudaniyah.

Berdasarkan hasil wawancara, observasi dan studi dokumen peneliti dapat menyimpulkan bahwa dalam mensosialisasikan ibadah haji dan umrah, PT Ulfa Rizki telah menerapkan prinsip-prinsip komunikasi Islam sebagaimana yang telah dicantumkan dalam Alquran yaitu menerpakan prinsip Qaulan Sadidan, Qaulan Balighan, Qaulan Maysura, Qaulan Layyinan, Qaulan Karima dan Qaulan Ma'rufa.

Untuk mensosialisasikan ibadah haji dan umrah, PT. Ulfa rizki juga menggunakan media dan memanfaatkan beberapa event besar. Diantaranya ialah sebagai berikut:

1. Media iklan berupa spanduk dan brosur

2. Media sosial seperti Youtobe, Facebook, Instagram dan metode konvensional yaitu dari mulut ke mulut.

3. Sosialisasi kepada Santri dan para orang tua santri di Yayasan Pondok Pesantern Tahfiz Quran As- Sudaniyah.

4. Sosialisasi dengan masyarakat sekitar misalnya jika ada event hari besar keagamaan, melakukan sosialisasi di mesjid samping tarvel PT. Ulfa Rezeki dengan bahasa yg persuasif ramah dan meyakinkan.

5. Sosialisasi dengan para murid-murid pengajian yang dilakukan setiap malam Jum'at dan Sabtu. Jadi kalau ada yang bertanya langsung datang ke travel ataupun tidak akan dijawab dengan bahasa yang persuasif dan santun.

Satu hal yang membedakan travel PT.Ulfa Rizki dengan travel lainnya, bahwa Direktur PT. Ulfa Rizki terjun langsung ke lapangan menjadi koordinator para jamaah sehingga beliau mengetahui kekurangan dana hambatan yang terjadi sehingga menjadi bahan masukan agar hal-hal tersebut dapat diatasi dan tidak terjadi kembali. Tentunya untuk kebaikan para jamaah dan travel PT. Ulfa Rizki.

\section{Kegiatan-kegiatan dan Fasilitas PT Ulfa Rizki dalam Mensosisalisasikan Ibadah Haji dan Umrah}

Berdasarkan hasil temuan penelitian, kegiatan- kegiatan yang diberikan PT Ulfa Rizki kepada para jamaah ialah sebagai berikut: 


\section{a. Kegiatan di Tanah Air}

Sebelum berangkat ke tanah suci, para jamaah dibekali pengetahuan tentang pelaksanaan ibadah haji dan umrah, yaitu

1) Manasik

Latihan manasik ini dilakukan tiga kali pertemuan di dua tempat yang berbeda yaitu dua kali dilakukan di Pesantren Tahfizh Quran As-Sudaniyah (pemimpin pesantren merupakan direktur PT Ulfa Rizki juga) dan satu kali dilaksanakan di Asrama Haji Medan. Pertemuan pertama adalah pertemuan awal agar para jamaah bisa tahu lebih banyak tentang haji/ umrah dan membuat persiapan untuk keberangkatan. Pertemuan kedua dan ketiga dilakukan latihan manasik haji/ umrah.

Disamping menjelaskan secara teori juga diringi dengan melakukan praktek atau peragaan. Para jamaah juga diajarkan bagaimana memakai pakaian ihram terutama bagi laki- laki, bagaimana pelaksanaan thawaf, sa'i, wukuf, tahallul, dll. Untuk mempermudah pemahaman jamaah, latihan manasik mempergunakan alat peraga seperti, miniatur kakbah, peragaan thawaf, wukuf, sa'i, tahallul dan sebagainya.

2) Zikir dan muhasabah

Kegiatan zikir dan muhasabah dilakukan satu bulan sekali dan para jamaah tidak dipungut biaya mengikuti kegiatan ini. Kegiatan zikir dan muhasabah ini menjadi salah satu keunggulan dari travel PT Ulfa Rizki karena memberikan kesempatan pada para jamaahnya untuk mengikuti zikir dan muhasabah yang itupun tidak dipungut biaya. Selain itu juga, tujuan dari kegiatan ini ialah menyambung tali silaturrahim antar para jamaah, direktur dan karyawan PT Ulfa Rizki. Kegiatan ini juga terbuka untuk masyarakat luas. Kegiatan ini dilakukan di Pesantren Tahfizh

Quran As-Sudaniyah yang beralamat di Jalan Willem Iskandar, Pancing II, Medan Tembung, Sumatera Utara.

3) Mengikuti pengajian belajar Alquran

Mengikuti pengajian belajar Alquran juga menjadi salah satu keunggulan PT Ulfa Rizki karena memberikan kesempatan pada para jamaahnya untuk memfasihkan bacaan Alquran mereka dan mendalami maksud ayat- ayat yang dikaji. Kegiatan ini tidak dipungut biaya dan dilakukan setiap sabtu dan minggu di Pesantren Tahfizh Quran As-Sudaniyah Medan. Tujuan lainnya dari kegiatan ini ialah 
mempererat tali silaturrahim antar para jamaah, direktur dan karyawan PT Ulfa Rizki. Kegiatan ini juga terbuka untuk masyarakat luas.

\section{b. Kegiatan di Tanah Suci}

Adapun kegiatan yang diberikan PT Ulfa Rizki kepada para jamaahnya di tanah suci ialah sebagai berikut:

1) Mekah

Selain melaksanakan kegiatan- kegiatan ibadah haji dan umrah, para jamaah PT Ulfa Rizki juga melakukan ziarah di beberapa tempat di kota Mekah. Adapun tempat- tempat yang diziarahi ialah

a) Gua Hira dan Jabal Nur

b) Jabal Rahmah

c) Gua Tsur dan Jabal Tsur.

d) Masjid Jin. Terletak di dekat Ma'la (kuburan umum di Mekkah)

2) Madinah

Para jamaah PT Ulfa Rizki juga melakukan ziarah di beberapa tempat di kota Madinah, yaitu

a) Masjid Nabawi

b) Makam Rasulullah.

c) Raudhah

d) Masjid Quba.

e) Jabal Uhud

f) Masjid Qiblatain (Masjid dua kiblat)

Sedangkan fasilitas yang ditawarkan dan diberikan PT Ulfa Rizki kepada para jamaahnya tergantung pada jenis umrah yang dipilih. Untuk program haji, PT Ulfa Rizki hanya melayani program haji khusus. Adapun rinciannya ialah sebagai berikut:

1) Umrah Reguler paket 13 hari

Bila para jamaah memilih jenis umrah ini maka biaya yang dikeluarkan ialah Rp 23.000.000,-. Penerbangan dengan menggunakan pesawat Garuda dan Saudi Airline dengan DP Rp 5.000.000,-

2) Umrah Reguler paket 10 hari

Bila para jamaah memilih jenis umrah ini maka biaya yang dikeluarkan ialah Rp 21.500.000,-. Penerbangan dengan menggunakan pesawat Garuda dan Saudi Airline dengan DP Rp 5.000.000,- 
3) Umrah Ramadan (12 hari)

Bila para jamaah memilih jenis umrah ini maka biaya yang dikeluarkan ialah

Rp 23.500.000,-. Penerbangan dengan menggunakan pesawat Scoot dan Singapore Airline dengan DP Rp 5.000.000,-

4) Umrah Full Ramadan

Bila para jamaah memilih jenis umrah ini maka biaya yang dikeluarkan ialah

Rp 35.000.000,-. Penerbangan dengan menggunakan pesawat Scoot dan Singapore Airline dengan DP Rp 5.000.000,-

5) Umrah Promo (paket 12 hari)

Bila para jamaah memilih jenis umrah ini maka biaya yang dikeluarkan ialah Rp 20.500.000,-. Berangkat bulan Januari, Februari, Maret, dan April dengan DP Rp 5.000.000,- dan pelunasan tiga bulan sebelum berangkat.

6) Umrah Promo (paket 12 hari)

Bila para jamaah memilih jenis umrah ini maka biaya yang dikeluarkan ialah hanya Rp 18.500.000,-. Berangkat bulan Februari, April, Desember 2019 dengan DP hanya Rp 2.500.000,- dan pelunasan tiga bulan sebelum berangkat.

Adapun paket yang dimaksud ialah sudah termasuk: a. Tiket pesawat, $b$. Hotel Mekah dan Madinah, c. Makan 3 kali sehari, d. Visa umrah, e. Ziarah/ City Tour, f. Mutawwif, g. Air zam- zam, h. Bagasi 30 kg, i. Koper besar, dua tas kecil, buku panduan, bakal baju seragam, dan j. Manasik

Sedangkan yang belum termasuk dalam paket ialah
a) Biaya PP Kualanamu
b) Perlengkapan liburan
c) Airport Tax and Handling
d) Paspor
e) Suntik miningitis
f) Laundry, rumah sakit dan kelebihan bagasi
g) Biaya muhrim bagi wanita dibawah umur 45 tahun, dan
h) Foto $3 \times 4$ dan $4 \times 5$ masing- masing 5 lembar
Adapun persyaratan lain yang harus dipenuhi ialah
a) Foto kopi Kartu Tanda Penduduk (KTP)
b) Foto kopi Kartu Keluarga
c) Membayar DP 
d) Pelunasan tiga bulan sebelum berangkat

e) Menandatangani surat perjanjian umrah (akad)

f) Mengikuti pengajian Alquran, dan

g) Mengikuti kegiatan zikir dan muhasabah

Untuk program haji, PT Ulfa Rizki menyediakan program haji khusus atau plus. Haji khusus atau haji plus menjadi alternatif masyarakat untuk berangkat haji lebih cepat, bagi yang tidak mau menunggu belasan tahun atau bahkan puluhan tahun baru berangkat. Namun dari segi pembiayaan, haji plus ini lebih mahal. Jamaah yang ingin berangkat dalam antrian yang tidak begitu panjang, bisa melakukannya melalui haji plus. Haji plus dan reguler mempunyai kesamaan pada proses pendaftaran. Pendaftaran sama-sama dilakukan Kementrian Agama, namun berbeda pada proses keberangkatan dan kepulangan.

\section{Respon Masyarakat Terhadap PT Ulfa Rizki}

Setiap ada tindakan yang dilakukan seseorang pasti memberikan respon kepada orang lain. Begitu juga dengan penerapan prinsip-prinsip komunikasi Islam yang dilakukan oleh PT Ulfa Rizki kepada masyarakat dalam mensosialisasikan ibadah haji dan umrah pasti ada respon dari para jamaahnya. Respon tersebut ada yang baik, biasabiasa saja dan ada juga respon yang tidak baik. Adapun respon masyarakat terhadap komunikasi direktur dan karyawan PT Ulfa Rizki yang ada di Medan adalah sebagai berikut:

1. Sebagian ada yang menerima penerapan yang dilakukan oleh direktur dan karyawan PT Ulfa Rizki. Ini terlihat ketika calon jamaah haji dan umrah mendegarkan dan mau bergabung dengan PT Ulfa Rizki. Ini terjadi kepada salah satu jamaah yang melihat brosur PT Ulfa Rizki dan ada niat untuk melakukan ibadah umrah kemudian langsung datang ke kantor dan mengurus administrasinya.

2. Sebagian ada yang mau bergabung tetapi dengan memenuhi permintaan calon jamaah. Ini terjadi kepada salah satu jamaah umrah yang mau ikut melaksanakan ibadah umrah apabila direkturnya mau langsung menemani mereka ketanah suci. Sebagaimana wawancara penulis dengan salah satu jamaah umrah yang telah melaksanakan ibadah umrah 4 kali berturut-turut.

3. Sebagian tidak memperdulikan penerapan komunikasi Islam yang diberikan oleh karyawan. Ini terjadi kepada calon jamaah yang hanya ingin bertanya tentang 
biaya dan administrasi untuk melaksanakan ibadah haji dan umrah saja dan membanding-bandingkan dengan travel yang lain karena belum ada niat untuk melakukan ibadah haji dan umrah.

\section{KESIMPULAN}

Berdasarkan analisis peneliti terhadap hasil penelitian dan pembahasan, maka dapat disimpulkan sebagai berikut:

1. PT Ulfa Rizki telah menerapkan prinsip-prinsip komunikasi Islam dalam mensosialisasikan ibadah haji dan umrah, sebagaimana yang telah dicantumkan dalam Alquran yaitu telah menerapkan prinsip Qaulan Sadidan, Qaulan Balighan, Qaulan Maysura, Qaulan Layyinan, Qaulan Karima dan Qaulan Ma'rufa dan untuk mensosialisasikan ibadah haji dan umrah, PT. Ulfa rizki juga menggunakan media dan memanfaatkan beberapa event besar. Yaitu media iklan berupa spanduk dan brosur, media sosial seperti Youtobe, Facebook, Instagram dan metode konvensional yaitu dari mulut ke mulut. Sosialisasi kepada santri dan para orang tua santri di Yayasan Pondok Pesantern Tahfiz Quran As- Sudaniyah, sosialisasi dengan masyarakat sekitar, dan sosialisasi dengan para murid-murid pengajian yang dilakukan setiap malam Jum'at dan Sabtu.

2. Adapun kegiatan yang ditawarkan dan diberikan PT Ulfa Rizki dalam mensosialisasikan ibadah haji dan umrah ialah untuk para jamaah haji dan umrah kegiatan terdiri dari kegiatan yang dilakukan di tanah air berupa latihan manasik, zikir dan muhasabah, dan pengajian Alquran. Ketiga kegiatan ini tidak dipungut biaya. Sedangkan untuk di tanah suci selain melakukan amalan- amalan haji dan umrah, para jamaah juga melakukan ziarah di beberapa tempat bersejarah di kota Mekah dan Madinah. Selain itu, PT Ulfa Rizki juga memberikan kesempatan untuk masyarakat luas untuk mengikuti kegiatan zikir, muhasabah dan pengajian Alquran. Mengenai fasilitas yang didapatkan para jamaah umrah tergantung pada jenis umrah yang dipilih sedangkan untuk fasilitas haji, PT Ulfa Rizki hanya menyediakan haji khusus atau haji plus dengan fasilitas yang lebih mewah dan harga yang lebih mahal dibandingkan haji reguler.

3. Respon masyarakat terhadap PT Ulfa Rizki dalam mensosialisasikan ibadah haji dan umrah bermacam- macam. Sebagian ada yang menerima dan mau bergabung, 
ada juga yang tidak menerima dan tidak memperdulikan sosialisasi yang dilakukan PT Ulfa Rizki dengan alasan- alasan tertentu.

\section{Saran}

Berdasarkan pada hasil studi penelitian tentang prinsip- prinsip komunikasi Islam oleh PT Ulfa Rizki dalam mensosialisasikan ibadah haji dan umrah, akhirnya peneliti memberikan beberapa saran penting, yaitu

1. PT Ulfa Rizki hendaklah tetap mempertahankan prinsip- prinsip komunikasi Islam yang telah diterapkan atau bahkan terus meningkatkan pemahaman tentang prinsip- prinsip komunikasi Islam yang disesuaikan dengan perkembangan zaman agar sosialisasi yang telah dilakukan menjadikan travel PT Ulfa Rizki menjadi travel yang besar, maju dan amanah.

2. PT Ulfa Rizki hendaklah memiliki website tersendiri sehingga memudahkan masyarakat untuk mengenal PT Ulfa Rizki, mengetahui kegiatan, fasilitas, persyaratan, prosedur pendaftaran, dll dan juga sebagai salah satu cara untuk mensosialisasikan ibadah haji dan umrah.

3. Direktur hendaklah menambah karyawan di PT Ulfa Rizki karena berdasarkan penelitian, karyawan PT Ulfa Rizki hanya berjumlah tiga orang. Untuk kedepannya, jika travel PT Ulfa Rizki terus berkembang dan maju, maka penambahan jumlah karyawan sangat dibutuhkan.

\section{Ucapan Terima Kasih}

Dalam proses penelitian ini, penulis telah banyak mendapatkan sumbangan pemikiran dan bimbingan dari berbagai pihak. Oleh sebab itu pada kesempatan ini penulis ingin menyampaikan penghargaan dan terima kasih kepada:

1. Kemenetrian riset, teknologi, dan pendidikan tinggi (RISTEKDIKTI) yang telah mendanai penulis sehingga penelitian ini dapat diselesaikan.

2. Yayasan Universitas Potensi Utama yang telah mendukung penulis baik dari sarana maupun prasarana selama proses penelitian ini.

3. Lembaga Penelitian dan Pengabdian Masyarakat (LPPM) Universitas Potensi Utama yang telah membimbing dan memberikan banyak arahan dalam penelitian ini. 
4. Pimpinan dan karyawan PT Ulfa Rizki yang telah menerima selama penelitian, memberikan data dan informasi kepada penulis.

5. Ketua dan anggota dalam penelitian ini, Nurul Saniah, S.Sos.I MA, Muallimah, M,Pdi, dan Indah Lestari S,Sos.I M.Kom.I yang telah sudi meluangkan pikiran waktu untuk menyelesaikan penelitian ini.

6. Semua pihak yang tidak dapat disebutkan satu persartu yang telah membantu penulis dalam menyelesaikan penelitian ini.

Akhirnya penulis hanya dapat mendoakan semoga Allah SWT berkenan melimpahkan rahmat dan karunia-Nya kepada kita semua agar penelitian ini dapat bermanfaat.

\section{DAFTAR PUSTAKA}

Cangara, Hafied. Pengantar Ilmu Komunikasi. Jakarta: PT Raja Grafindo Persada, 2009.

Departemen Pendidikan dan Kebudayaan. Kamus Besar Bahasa Indonesia Edisi Ketiga Jakarta: Balai Pustaka, 2001.

Effendy, Onong Unhjana. Ilmu Komunikasi Teori dan Praktek. Bandung: PT Remaja Rosdakarya, 2005.

Faisal, Sanapiah. Format-format Penelitian Sosial, Jakarta: PT Raja Grafindo Persada, 2008.

Fajar, Marhaeni. Ilmu Hadis Teori dan Praktik. Jakarta: Graha Ilmu, 2009.

Kholil, Syukur. Komunikasi Islam, Bandung: Citapustaka Media, 2007.

M.B \& Huberman, A.M., Analisis dalam Kualitatif, terj. Tjeptjep Rohendi Rohidi. Jakarta: UI Press, 1992. 